\title{
Does the Manual Help? An Examination of the Problem-Solving Support Offered by Manuals
}

\author{
Hans van der Meij
}

\begin{abstract}
This paper examines whether manuals provide adequate help for users who are experiencing a problem. First, an outline is given of the main stages in problem-solving. This outline offers a broad framework for the two studies of current practice that follow. The first study focuses on the accessibility of help. It examines how often manuals fail to offer the right keywords, and how often they have not marked or have misplaced problemsolving information. The main conclusion is that most manuals pose formidable obstacles to accessing help. The second study investigates the main reasons for presenting problem-solving information as a Regular Step, as a Skipable Action, or as an Afterthought. The main finding is that writers or typographers tend to opt for a different design than what is theoretically best.
\end{abstract}

$\mathbf{M}$ OST handbooks for technical writers give concrete suggestions [1]-[3]. A prominent guideline is to number the consecutive actions in a procedure. This "almost guarantees fewer mistakes" [2, p. 234]. How often is this advice followed in practice? The answer is that we don't know. No inventory on this matter exists. Inventories are also absent for most of the other advice given in the handbooks.

The handbooks also suggest that it is wise to consider the competition. Such an inventory offers a perspective from which to (re)consider one's own product, yielding new ideas on content, format, layout, and access methods. Is this advice followed? Perhaps. Yet, again very few inventories have found their way into the literature.

The dearth of inventories is unfortunate for those who want to get to know the competition at little cost. But, more importantly, it also impedes the advancement of technical writing as an applied science. Inventories are vital for their state-of-the-art descriptions. Among other benefits, they reveal when writers follow the advice of handbooks and when they do not. Such insights can stimulate better practices and more refined theories. In short, inventories are crucial for tying theory with practice.

This paper reports on an inventory concerning problemsolving information in manuals. Problem-solving information is defined here as help for handling conflicts that interrupt or block actions. Such information may assist users in detecting, defining, diagnosing, and correcting problems, but only one of

Manuscript received January 1996; revised June 1996.

The author is with the Faculty of Educational Science and Technology, Department of Instructional Technology, University of Twente, P.O. Box 217, 7500 AE Enschede, The Netherlands.

Publisher Item Identifier S 0361-1434(96)06707-0. the four elements is needed to label a section as containing. problem-solving information. The following example shows a section with three elements [description added]: "If the text Drive not ready reading drive $\mathbf{A}$ appears [detection], you have not inserted the diskette deeply enough into the drive [diagnosis]. Insert it again so that the button pops up. Then type 1 [correction]."

One reason for analyzing problem-solving information is that problems can have a considerable effect on user motivation and acceptance of a program and manual. In addition, research has shown that users frequently engage in problem solving. For example, it has been found that between 25 and $50 \%$ of the user's time in word processing is spent on problem solving [4]-[7].

The inventory begins with an outline of the main stages of problem solving. This description offers a broad framework for examining current practice. Two studies are then reported. The first focuses on obstacles to accessing problem-solving information. It examines how often manuals fail to offer the right keywords, and how often they have not marked or have misplaced the problem-solving information. The second study focuses on the presentation of problem-solving information. Among other aspects, this study brings to light some of the reasons one might have for marking and placing the information in a particular way.

\section{STAGES IN PROBLEM SOLVING}

The processes people go through in problem solving have been examined in various disciplines and for various types of problems. For example, studies have considered how people search for information in textbooks and manuals, how research problems develop, and how people solve problems in games such as chess and bridge [8]-[14]. Most of these studies suggest that problem solving progresses through three main stages (see Fig. 1).

\section{Stage 1: Experiencing a Problem}

All problem solving begins with a user experiencing a problem. Some authors call this problem finding to indicate that the person must literally find the problem [8], [13], [15]-[17]. This stage typically requires two activities:

- seeing the problem

- paying attention to the problem. 


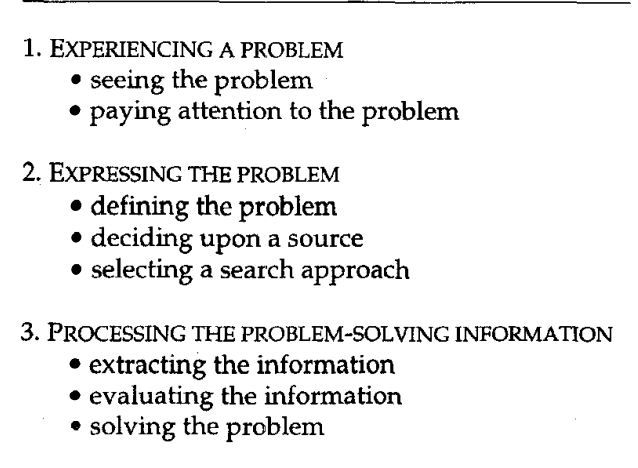

Fig. 1. A processing model of problem solving, indicating the main stages and their activities.

First, the user must see the problem. The person must become aware of, or notice, something troublesome or problematic. This may be triggered by something external, for instance, the appearance of an error message on the screen. Seeing the problem may also be triggered internally, originating with the user. For example, the user may simply wonder whether some actions were executed correctly.

Second, the user must decide to pay attention to the problem. Users do not deal with all problems they face. Some problems are ignored simply because they are perceived as minor inconveniences. The user must find the problem important enough to pay attention to it. An extreme example of such a situation is task obstruction.

The main outcome of this stage is one of continuing attention to a still vague problem. There is no visible solution yet. A user may, of course, become restless, stop doing things, or give other nonverbal signs of perplexity. But there is hardly ever any proof that a user is really experiencing a problem. It is only when a user expresses the problem that one can infer that a problem has been experienced.

\section{Stage 2: Expressing the Problem}

In this stage, the user must come to grips with the problem. The problem must be articulated, or defined, which is why some authors call this stage problem formulation. The user must address the question "What's the problem?" [18]. In addition, the user must engage in search behavior, deciding what source to consult and how to approach that source. For example, the user may decide to seek help from a colleague and to indicate to that person the probable cause of the problem.

The processes of problem definition, of source selection, and of search strategy often interact. For example, for systematic problems, users are more likely to seek outside help than for simple slips (e.g., typographic mistakes). Likewise, users may redefine their problem after receiving some information. To simplify this presentation, the main user activities in this stage are discussed separately. These activities are as follows:

- defining the problem

- deciding upon a source

- deciding upon a search strategy
The user must define the problem. For many people, this is one of the most difficult processes in problem solving [13], [19], [20]. It requires the user to come to some understanding of the nature of the problem. The user may search the screen for cues in the hope of better comprehending the problem. The user may also reflect about the actions that preceded the problem, or consider the context in which it arose. These reflections can help in defining the problem and its probable cause(s). The user may end up with a well-defined or an illdefined problem. With a well-defined problem, the user has a fairly precise idea of what to look for in the source, and the search may proceed in a rather straightforward way to locating this. With an ill-defined or fuzzy problem, the user is less clear of what to look for, and the search may be more erratic.

The user must also decide whether the problem is amenable to help and worth a sustained effort [13]. The user must believe that the problem can and should be better understood or solved. Clearly, this is not always the case. Users sometimes abandon problems after knowing what they are. A typical example would be the novice who knowingly decides to leave a hidden code in a text document because it doesn't cause a problem or because the novice doesn't know how to remove it.

The user must decide upon a source of information. Often a user has a number of options from which to choose. For example, the user may elect to study the manual, to examine the online help, to seek assistance from a colleague, or to consult a help desk. Many factors may affect this choice: selfconfidence, ease of access, confidentiality, problem definition, complexity, context, familiarity with the source, and so on [13], [21], [22]. In addition, all of these factors may interact in various ways. For example, a user who has just accidentally erased the contents of a hard disk may decide to consult the manual to avoid being blamed or shamed by a helper. Or, when trying to solve an ill-defined problem, most users only opt for the manual when there is no willing and able helper nearby; they tend to prefer a personal source because of the opportunity to negotiate meaning, to build up a mutual understanding of the problem.

The user must decide upon a search strategy. Source and search strategy are closely related. A user consulting another person may, for example, cautiously inquire first if that person is free to help and then to volunteer information about the problem. In consulting a manual, the user has a choice between an indirect and a direct search.

In indirect searches, users looks for references, pointers that hint at the presence of problem-solving information somewhere in the manual. The best and most preferred places for these pointers are the table of contents and the index [20], [23]. For example, on a rating scale with a score of 10 signifying highest utility value, college students placed the index on top, with a rating of 9.4. The table of contents was a strong second, with a score of 8.2 [23].

Empirical studies show that searching the index is no guarantee to success, however. Poor qualities of the index and poor strategies of users have been found to limit the usefulness of indexes [20], [23]-[27]. For example, one study reports that $75 \%$ of the searches of students were successful when the keyword they had in mind was presented in the index, but that 
only $4 \%$ of their searches were successful when they searched for a nonindexed keyword [23].

In direct searches, users look in the main body text itself in the hope of finding relevant information. In this search approach, the user does not immediately start reading [10]. The user may be guided by marks on the page, but also by a preconceived idea of where problem-solving information is likely to be found. For example, the user might look for a help or undo header, a section starting with the word Note, a first-aid icon, and so on.

In general, little is known about the factors that affect the choice of a search strategy. As indicated earlier, the choice is often determined by how well the user succeeds in defining the problem. The search is likely to be quite different for a well-defined problem than for an ill-defined one. But the user's familiarity with the manual and the user's skill in handling a particular search strategy are also important factors that have yet to be investigated [19], [28], [29].

At the end of this stage, the user is reading some information from the manual which he or she believes to be pertinent to the problem at hand.

\section{Stage 3: Processing the Problem-Solving Information}

In this stage, the user must process the information offered by the source. The first activity here is information extraction. The user must read and comprehend the information. It should then be related to the problem definition, or integrated. Then the user must judge whether the information offers a satisfactory solution to the problem. Finally, the user must apply the information. In short, the three main user activities in this stage are the following:

- extracting the information

- evaluating the information

- solving the problem

In general, extracting the information is easy when the problem is relatively simple or well-defined and the information is presented as running text. In contrast, people find it difficult to extract information when they are facing a complex or illdefined problem for which they must extract their information from a table, a map, a flow-chart, a drawing, or a combination of text and graphic [9], [10], [30], [31]. For example, one study found that about $50 \%$ of college students did not succeed in extracting the proper information from the graphs and illustrations presented to them [30].

The user also evaluates the information. The user must decide whether the information offers a satisfactory solution to the problem. The success of this effort largely depends on what the user already knows about the topic [29], [32]. If no relevant facts are found, the user may decide to abandon or to continue the search. In the latter case, the user goes back to an earlier stage or action. The user may then try a new problem definition or source, or simply read on until some satisfactory information is found.

The last activity is solving the problem. In general, users engage in one of two approaches: a corrective or a (re)constructive method [6], [7], [33]. In a corrective method, the user removes the obstacle(s) to regular task achievement. For example, the user may erase a hidden code in a document. In a (re)constructive method, the user simply tries to perform the constructive actions again, hoping to do it right the second time by paying more attention. Occasionally, the user takes (additional) precautions so that the same problem will not happen again.

The most desirable outcome of this stage would be that a user has understood the problem, solved it, and taken precautions so that it would not occur again. Not all problems allow for such an outcome. Sometimes a user should be content merely with understanding. Sometimes merely a temporary solution is possible.

\section{STUDY 1: ACCESSIBILITY}

Users face a number of obstacles when they try to solve problems with the aid of a manual. Three kinds of obstacles are examined in this study: 1) no keyword in the table of contents or index, 2) no marking of problem-solving information, and 3) misplacement of problem-solving information.

No Keyword: Not having the right keyword in the table of contents or index can pose a formidable barrier. Research shows that the presence of the right keyword strongly improves the chances that users can find the information they seek [23], [24], [26]. For example, college students have been found to be about $30 \%$ more successful when the index contained a keyword they had in mind [24].

Whereas all writers probably agree that they should present the right keywords in the table of contents or index, doing so can be very hard to accomplish. Creating entry terms that suit a variety of problems as well as audiences is a very taxing task [34].

In view of the difficulty of keyword creation, the following approach for measuring the obstacle of "no keyword" was taken. A systematic search for general keywords on problem-solving information was conducted through tables of contents and indexes. This search concentrated on the presence of keywords such as "help with problems," "errormessages," "troubleshooting," "correcting problems," "mistakes," and "problem solving." Simultaneously, if a specific keyword on problem-solving information was encountered, this too was registered. Typical examples are keywords such as "tabs-problems with," "salvaging unreadable disks," and "errors in using replace." The outcomes indicate how often the tables of contents and indexes of the manuals offer no general or specific keyword on problem-solving information.

No Marking: Another important obstacle can be the lack of any marking of problem-solving information. During scanning, users strongly rely on markers to find what they are looking for. Markers enable users to "read" at a rate of about 600 words per minute [35]. After locating a potential target, users slow down to process the contents in some detail.

The writer or typographer can visually cue the presence of problem-solving information by surrounding it with (extra) white space, by adding a picture or an icon, by boxing it, and by varying letter size and style. Cueing can also occur 


\section{Disturbances in the reception of your television}

Most of these problems are not caused by failures of the television itself, but by outside causes.

$\begin{array}{llll} & \begin{array}{l}\text { Problem Type } \\ \text { Cause }\end{array} & \text { Remedy } \\ & \begin{array}{l}\text { Sparks } \\ \text { You may notice } \\ \text { disturbing } \\ \text { stripes running } \\ \text { horizontally } \\ \text { over your screen. }\end{array} & \begin{array}{l}\text { These stripes } \\ \text { are caused by } \\ \text { cars, motors, } \\ \text { refridgerators } \\ \text { and so on. }\end{array} & \begin{array}{l}\text { Unfortunately, } \\ \text { there is no } \\ \text { remedy here. }\end{array} \\ \end{array}$

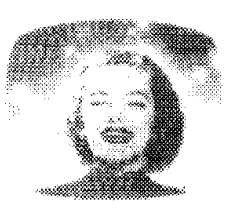

\section{Glitter}

Your screen may show a dim light, or some glittering.

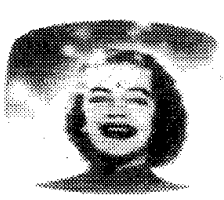

Ghost Images

You may see double images.

\section{The signal that your television receives is too weak.}

\section{A good antenna will bring about serious improvements.}

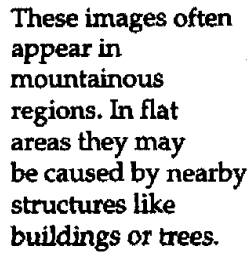

\author{
A very precise \\ positioning of \\ the antenna will \\ surely be \\ successful.
}

Fig. 2. There are several markers that catch the eye. The two most prominent ones are the pictures and the table-like format which stand out because all other information in the manual is presented as regular text (paragraphs). The presence of problem-solving information is also cued by the general signal words problem type, cause, and remedy, and by the bold, specific signal words sparks, glitter, and ghost images. Note also that the pictures define the problem so that users can almost immediately see whether they are likely to find information on the problem they are experiencing. Note also that the three-column format models problem decomposition.

with words such as problem, please note, help, or attention. Fig. 2, from a television manual from around 1960, shows an example in which users can hardly fail to notice the problem-solving information. The main question, of course, is not whether writers or typographers can, but whether they should, mark the problem-solving information. There are at least two arguments in support of a distinct marking. The first is that users frequently consult manuals to find problemsolving information [6], [7]. The second argument is that users scan before they read, which gives marked problem-solving information a much better chance of being noted [20], [36], [37].

The obstacle of "no marking" was examined as follows. The experimenters systematically read - at a slow pace-a random selection of maximally 25 pages from each of 60 manuals. The first example of problem-solving information encountered was analyzed. An occurrence was scored as marked if a visual or verbal cue made the problem-solving information stand out on the page. The data gathered in this way show how often the problem-solving information is marked.

Misplacement: Problem-solving information is also hard to find if it is not presented where users expect it. Where do they expect to find problem-solving information? Observations suggest that users are most likely to look (first) for such information within or immediately after procedures [20], [37].

The obstacle of misplacement was examined as follows. A subset was drawn from all examples of problem-solving information gathered while examining the obstacles "no keyword" and "no marking." This subset consisted of the sections in which the problem-solving information consisted of just one or two sentences. The sections were scored as appearing in the vicinity of a procedure, or being placed elsewhere. The outcomes indicate where writers prefer to place these sections.

\section{Examined Manuals}

A sample was gathered of 60 manuals. The sample included 29 software manuals for applications such as FrameMaker, Lotus 1-2-3, PageMaker, PowerPoint, Word, WordPerfect, and Works. There were 24 manuals for system software such as Hypertalk, MS DOS, Norton Utilities, System 7, UNIX, and Windows. The 7 hardware manuals discussed topics such as a printer, a video display terminal, computer, and an accelerator card. There were 8 manuals from 1980-1985, 25 from 1986-1990, and 27 from 1991-1994. The sample was 
TABLE I

The Mean Chance of Finding Problem-Solving Information PER SEARCH STRATEgY

(For the tables of contents the results also include the outcomes for the three independent searches therein; i.e., a search was conducted on keywords in titles for chapters, paragraphs, and appendixes.)

Mean Chance of Success (\%)

$\begin{array}{lll}\text { Main Body Text } & 62 & \\ \text { Index } & 57 & \\ \text { Table of Contents } & 83 & \\ \text { Chapter } & & 20 \\ \text { Paragraph } & & 70 \\ \text { Appendix } & & 22\end{array}$

stratified and balanced for type of documentation. That is, there were 20 tutorials, 20 reference guides, and 20 user guides.

No effects of age of the manuals or of type were found. Therefore, only the main effects for the three obstacles are reported. All codes yielded adequate values for reliability between the two experimenters who scored the data (Cohen's kappa was 0.70 or higher) [38].

\section{Results}

A user who examines the table of contents, or the index, or the main body text of these manuals has a $67 \%$ chance of finding some problem-solving information. While this seems to show a fair degree of success, it is in fact an alarmingly low figure, suggesting that manuals pose formidable obstacles. It overestimates the chances of real users with real problems. The study was conducted in a systematic and exhaustive way with the experimenters accepting any problem-solving information encountered as a "find." Most users are not as systematic and thorough, and they will also not be satisfied by just any kind of problem-solving information. They search impatiently and look for specific help. The information they need must address their particular problem. In short, although the mean success rate is already well below $100 \%$, even the $67 \%$ score is a far too optimistic prediction of the chance that users will find the help they need.

Table I details the outcomes. A statistical test showed no difference between searches. The chance of finding problemsolving information was the same for the search through the main body text, via the index, or via the table of contents $\left(\chi^{2}=5.68, d f .2\right.$, n.s. $)$.

No Keyword: The chance of finding problem-solving information via the table of contents was $83 \%$. Table I shows that a considerable number of manuals present problem-solving information in a chapter or appendix. However, it is most often presented in paragraphs.

The indexes yielded a success rate of less than $60 \%$. This is partly because $22 \%$ of the manuals were without an index. For manuals with an index, the success rate was around $80 \%$, which is nearly the same as for the table of contents. But even in these indexed manuals it may be difficult to access the problem-solving information because $32 \%$ of the indexes did not include the general keywords error, or error message, or message, or problem, or problem solving, or help.
The distribution of keywords differed significantly for the tables of contents and indexes $\left(\chi^{2}=4.39, d f .1, p<0.05\right)$. In the tables of contents, general keywords dominated (62\%). This finding agrees with the view that the table of contents must give users a comprehensive view of the contents of a manual. For the indexes, the opposite was found; $90 \%$ of the keywords were specific. This finding agrees with the view that an index should offer specific references and precise page indications. Fig. 3 presents an overview of the various keywords that were found.

Some critics might argue that the study underestimates the chances of finding references to specific problems in the tables of contents and indexes. To counter this argument, a "reverse access" test was run on a subset of the data. This subset consisted of the examples found in the main body text that were long enough to warrant referencing (i.e., sections of at least one paragraph). For each example, a set of keywords was generated, and the table of contents and index were examined to see if one keyword from this set was mentioned. Also, all references to the relevant page(s) were checked for keywords that might have been overlooked by the experimenters. The test showed that the majority of paragraphs could not be accessed; $64 \%$ of the paragraphs with problem-solving information were not referenced. The results were essentially the same for the table of contents and index, with $81 \%$ and $69 \%$ misses, respectively $\left(\chi^{2}=2.88, d f\right.$. 1, n.s. $)$. This test thus strongly supports the "no keyword" claim. The majority of sections of problem-solving information are not accessible via the table of contents or index.

No Marking: The majority ( $86 \%$ ) of the problem-solving information was not marked at all. Only $14 \%$ was easy to find due to the presence of an icon, heading, signal word, lines, or some other design feature that made the information stand out on the page. Fig. 4 illustrates one of the best examples from the sample.

The data strongly suggest that writers or typographers do not find it important enough to (visually) distinguish the problemsolving information as such. This contrasts with the view that important information types in a manual, such as procedures and problem-solving information, should each be marked in their own distinct way [2], [6], [33], [39], [40].

Misplacement: An absence of any marking does not necessarily defeat scanning. Users can still easily detect problemsolving information if it is positioned where they expect it. Research suggests that they expect a positioning within or immediately after procedures [37]

Some $57 \%$ of the problem-solving information was placed near the procedures. Clearly, this also means that $43 \%$ of these sections are very hard to find. Fig. 5 illustrates the difficulty.

\section{Discussion}

The results from Study 1 allow no other conclusion than that most manuals pose formidable obstacles to finding problemsolving information. Among various findings, the data show that:

- $64 \%$ of the paragraphs with problem-solving information are not referred to in the tables of contents or indexes 


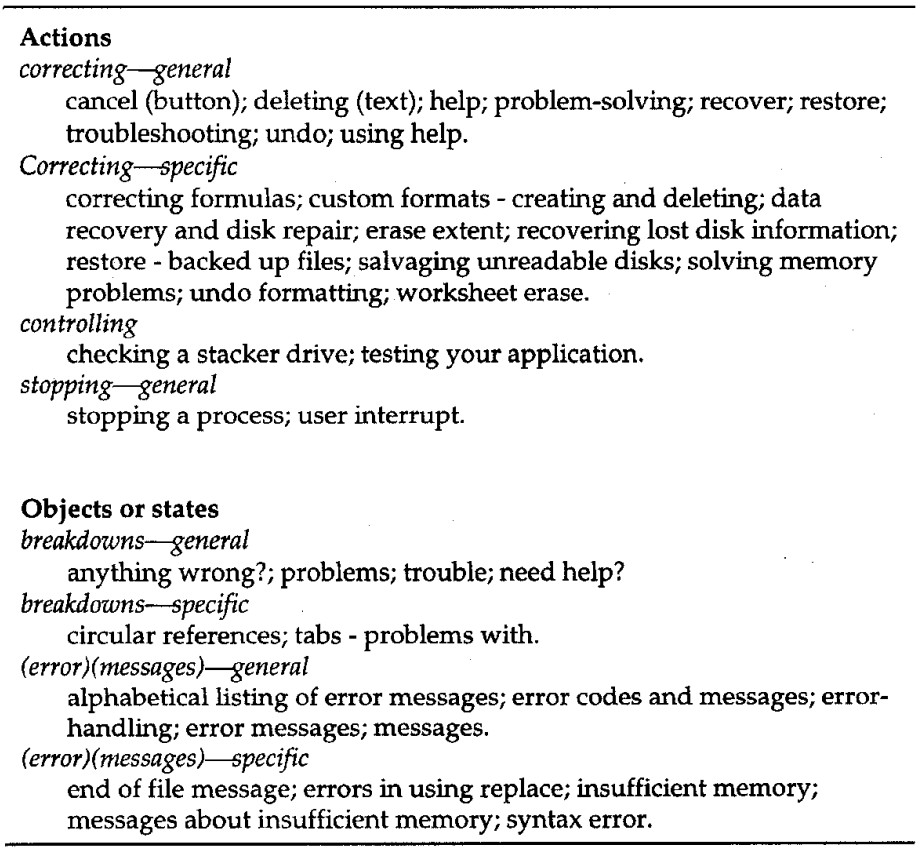

Fig. 3. An overview of the keywords on problem-solving information found in the tables of contents and indexes. Keywords with actions were found mainly in titles of paragraphs, and keywords describing objects or states were found mainly in titles of chapters and appendices $\left(\chi^{2}=16.71, d f .2, p<0.001\right)$.

- $17 \%$ of the tables of contents do not include any keyword on problem-solving information

- $22 \%$ of the manuals are not indexed at all

- $32 \%$ of the indexes lack keywords such as error, messages, problem solving, and help

- $86 \%$ of the problem-solving information is not marked in any way

- $43 \%$ of the problem-solving information is not placed where users are most likely to search

In short, most of the problem-solving information in manuals is inaccessible. More efforts are needed to overcome the obstacles of "no keyword," "no marking," and "misplacement" of problem-solving information.

Handling the No-Keyword Obstacle: The no-keyword obstacle should probably be handled in the same way as finding good keywords for headings and indexes. In other words, it requires a good deal of skill and effort to do a proper job. Within this paper only a few suggestions can be given.

One-it often pays off handsomely to begin by creating an overview of the primary and secondary keywords on problem solving. Writers might want to start with a list of general keywords. For example, they could use the italized keywords in Fig. 3. This list could then serve for generating and structuring the specific keywords that are most relevant for the task at hand.

Two-the filled-in list can be used to decide which keywords should go where. Typically, the writer must choose between the table of contents and the index. Writers might want to consider here that keywords often serve the dual purpose of facilitating access and helping users express their problems. Keywords can help users clarify the kind of information sought and thereby help transform an ill-defined situation into a well-
If you chose the wrong type of port, the wrong specifics for a serial port (such as the baud rate), or the wrong printer port number, then you must redefine your printer for WordPerfect before you can print. If you need to redefine your printer port, see Appendix A.

Trap: The message "Press "Go" to continue" indicates that WordPerfect is waiting for a signal.

At certain times, WordPerfect will not print until you signal that you are ready. When you see on the Control Printer menu, the message "Fix printer--Press "G" to continue," one of the following problems might exist:

- You defined your printer for manually fed paper, or you are using a form defined as not initially present in your printer. (Appendix A describes how to define your printer and printer forms.) WordPerfect is waiting for a signal that the paper has been inserted. Insert the paper and type G, Go (start printer) ( 4 or G).

-

Fig. 4. The icon immediately draws the attention. For users who do not yet known the meaning of the icon, the word Trap is useful, suggesting that a warning or some problem-solving information is presented. The error message specifies the kind of problem that is discussed. Its inclusion in the text facilitates the users' search for problem-solving information.

defined one. For this reason, it is advisable to present specific and general keywords in both the table of contents and the index, but to vary their dominance. The table of contents is best for presenting the majority of general keywords. The index is best for presenting specific keywords.

Three-the use of a (check)list with keywords could alert writers to the absence of important signal words such as error, error message, message, problem, problem solving, or help in their indexes. In addition, such a list may also partly solve the 
With Block on, press the PRINT (Shift + F7) key. [Pulldown menu: File (F), Print (P).] Now instead of displaying the Print screen, WordPerfect prompts

Print block? No (Yes)

Type $Y$ to print the block; type $N$ or press the ENTER key to abort the print.

For sheet-feeder and continuous-paper users, when the paper is present in the printer, the printing will begin immediately. If the paper is not initially in the printer, or your printer has been defined for manually fed paper, the computer may pause and sound a beep, indicating that it is waiting for a signal that you have placed a fresh piece of paper in the printer.

Fig. 5. A typical example of "hidden" problem-solving information. In the absence of any visual marking, scanning users may find it very difficult to find the help they are looking for.

problem of using the right words and of choosing the right word order. Special attention is needed for the inclusion of words such as mistakes, errors, and error messages because of the emotional reactions these terms may evoke. For example, some writers prefer not to present the keywords error or error message in the table of contents because they believe users and potential buyers see this as a signal of a flawed program.

Four-writers might want to add secondary entries to general keywords in the index. The inventory indicates that writers tend not to specify general keywords. For example, only two indexes had secondary entries to the keyword error messages. With a (check)list it is relatively easy to create these. For example, to the primary keyword error messages writers could secondary entries by adding actions (...-understanding, $\ldots$-removing, ...-deactivating), and objects or states (...about insufficient memory, ....-during printing, ...-during installation). Such secondary entries further characterize the problem and thereby fit the purpose for which users sometimes scan the index [34]. Beginning with a general term, users look at subordinate keywords in order to narrow down their problem definitions [20]. As an aside, it is noted here that writers often do not present the original message in the manual [38]. This is unfortunate because such messages express the problem and thereby serve as the first cue in scanning.

Five-a different suggestion altogether is to work with empirically based keywords, which could make the index as much as five times more successful [26]. However, this option seems feasible only for well-studied software programs such as word-processors.

Six-writers probably ought to check whether their index is long enough. As a rule of thumb, writers should aim for an index of $5 \%$ of the size of the manual [1], [41]. For a manual of 200 pages, this would mean a 10-page (two column) index. This is a tough criterion. The mean score for the indexes. of the manuals in the present study was $2.9 \%$, and only six of the manuals satisfied the $5 \%$ criterion.

Handling the No-Marking and Misplacement Obstacles: A discussion of how one might go about removing the barriers of no marking and misplacement is deferred until after the next study. This study addresses the basic question of whether it

\author{
Input by hand \\ It is also possible to give paper input by hand to the printer in case \\ the current has been switched off. This procedure is as follows: \\ 1. .... \\ 2. $\ldots$. \\ 3. $\cdots . .$. \\ 4. Turn the knob clockwise until you can clearly see the top of the \\ paper coming out from the lid. \\ 5. If the paper is positioned somewhat out of tilt, you should \\ press the lever forward and reposition the paper by hand. \\ Next, you press the lever backwards again. \\ 6. Close the cover.
}

Fig. 6. "Regular Step"-variant. Problem-solving information is placed within the procedure (i.e., step 5) and marked the same as the regular steps in the procedure.

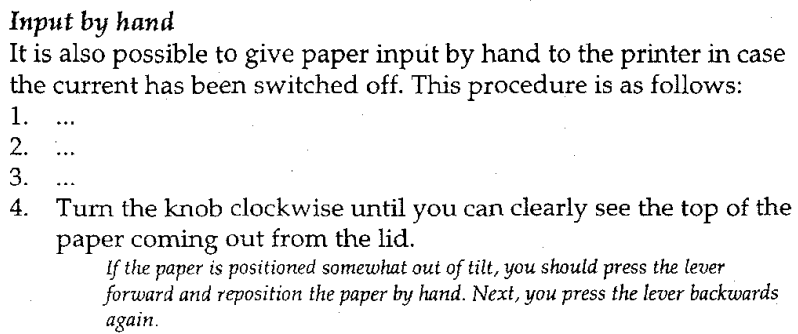

6. Close the cover.

Fig. 7. "Skipable Action"-variant. Problem-solving information is placed within the procedure and marked to make it stand out on the page.

is important to opt for the distinct marking and placement of short sections of problem-solving information. Some reasons for doing so have already been indicated in this paper, but these were raised mainly in support of scanning. The accessibility of problem-solving information was examined for a user who consults the manual after having been confronted with a problem.

Clearly, users also often need help while processing the manual. Study 2 examines this usage. It focuses on arguments for marking and placing problem-solving information so that readers can gain the most profit. In addition, the study examines whether theory and practice agree on an optimal design solution.

\section{STUDY 2: \\ DESIGN RATIONALE}

This study focuses on the marking and placement of short sections of problem-solving information. Typically the manuals of Study 1 use three variants for their presentation. Problem-solving information is presented as a Regular Step, a Skipable Action, or an Afterthought (see Figs. 6-8). The main differences between these variants have to do with marking and placement.

Marking: Why should one mark short sections of problemsolving information? First, marking is vitally important for 


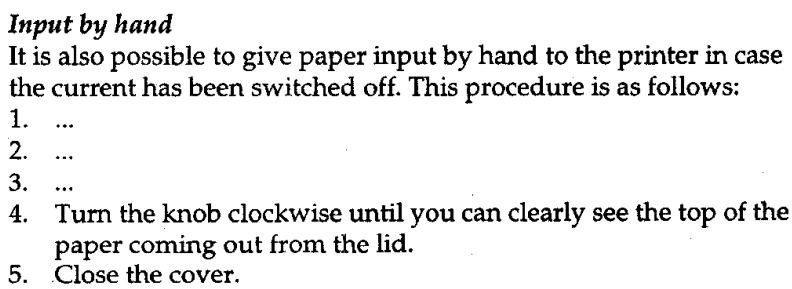

If the paper is positioned somewhat out of tilt, you should open the cover, press the lever forward and reposition the paper by hand. Next, you press the lever backwards again and close the cover.

Fig. 8. "Afterthought"-variant. Problem-solving information is placed in the paragraph that follows right after the procedure. It is presented as plain text, not marked, the same as all other conceptual information presented in the paragraphs.

scanning. Marks catch the user's eye. Second, marking can prevent problems for readers. When the problem-solving information is marked differently than the regular steps, the user cannot confuse one for the other and accidentally execute some corrective actions. Third, users will come to recognize the problem-solving information as a special information type that can be skipped at will or consulted when needed (as in Fig. 7). A special type of consulting was observed in an experiment. After having completed a procedure without failure, users would start the task again and do something wrong on purpose in an effort to practice problem solving [7], [33].

Placement: The best place for presenting short sections of problem-solving information is within or immediately after a procedure [6], [7], [33]. In the vicinity of a procedure it better supports problem detection, definition, diagnosis, and correction. One argument for this just-in-time presentation is that users sometimes make mistakes of which they are unaware and which are not flagged by the program. In these cases, users need help to catch problems early. Well-placed problemsolving information offers such help. It decreases the chances that problems pile up, that a multitude of key-presses lie between the onset of the problem and the moment of detection, which makes diagnosis difficult if not impossible [33]. Another argument is that users sometimes ask themselves "Is this right?" after having wrongly executed one or more actions. A timely presentation of problem-solving information gives the needed feedback by signaling the mistake. By suggesting what might have gone wrong, well-placed problem-solving information can also help users in drawing the right diagnosis. A third argument is that most error messages on the screen do not tell the user how to solve the problem. So for these messages too the presence of well-placed problem-solving information in the manual can be important.

To find out the main reasons for choosing a particular mixture of marking and placement of problem-solving information, a group of student designers was shown an example of each variant-without their descriptive captions-and asked to state why writers might want to present problem-solving information in that way. After having done so, the students indicated which variant they thought best. A comparison of the students' choice with the choice that was found most in the manuals was carried out.

\section{Subjects}

Forty students participated in the study. All students were volunteers and in their third or fourth (last) year of study for a Masters Degree at the Faculty of Educational Sciences and Technology at Twente University. These students are trained to become designers. They specialize in the presentation of information for instructional purposes, and they are welltrained in document design.

\section{Results}

The main arguments for presenting problem-solving information as a Regular Step (see Fig. 6) are that:

- it forces a controlling action

- problem-solving information is presented as something normal, not as odd or disturbing

- it is well-timed, placed where users need it most

The first two arguments pertain to marking. Students frequently mentioned how the presentation might trigger a user action the same as a regular step would. By its presentation, the problem-solving information inherits the qualities of regular steps. In addition, users are forced to do something to monitor their behavior. Typical reactions in this respect were "it's kind of hard to skip," "it takes users by the hand," and "you know when to be careful." The presentation also conveys the idea that it is normal for users to encounter problems. Problems are treated as part of what users must learn to deal with, an approach that may help reduce the likelihood of problems having an upsetting and frustrating effect. The final argument concerns placement. Typically, students indicated that the Regular Step variant offers problem-solving information "where things are likely to go wrong," "where it is immediately useful," and "where the action is."

The main arguments for presenting problem-solving information as a Skipable Action (see Fig. 7) are that:

- it is clearly distinguished from other information types

- its presentation draws the attention, which can be very helpful for users who search for problem-solving information

- it can easily be skipped-if you know the convention

- it is well-timed, placed where users need it most

All but the last argument concern marking. The presentation in the Skipable Action variant literally helps users see some other type of information in the procedure: "Users can hardly fail to perceive this as a special type of information. At the very least they will immediately know that this is not the same as a regular instruction." The students also noted that the distinct marking supports different ways of handling the manual: for scanning and reading to learn or do. In addition, some students noted that a distinct marking is not just handy for locating problem-solving information, but also for enabling users to skip it easily when not needed: "The user is offered a 
TABLE II

The Preferences of Students and Writers for Presenting Short Sections of Problem-Solving Information (Scores in percentages.)

\begin{tabular}{lrr} 
Preferences of: & Students (\%) & Writers (\%) \\
\hline & & \\
Presentation Type: & & \\
Regular Step & 8 & 7 \\
Skipable Action & 78 & 30 \\
Afterthought & 15 & 63 \\
\hline
\end{tabular}

choice-provided that he or she knows what to expect here." The last argument, which refers to placement, is the same as for the Regular Step variant. The value of a just-in-time presentation was also mentioned.

The main arguments for presenting problem-solving information as an Afterthought (see Fig. 8) are that:

- it cannot be confused with instructions

- it leads to clean, crisp instructions

- being set apart it can easily be refound

- it follows the rule that regular instructions should be placed before the exceptions

All arguments for this variant concern placement. Many students mentioned that the Afterthought variant helps users keep problem-solving information apart from the procedure. This leaves the procedure unspoiled: "There is no needless information in the instructions." The students also mentioned that users might be able to access the information relatively easily because it was presented in the important first sentence of the new paragraph. The students' last argument refers to an instructional design principle which suggests that it is best to confront learners first with the regular case and then to inform them about exceptions.

Tying Theory with Practice: When asked which of the three variants the students preferred, the outcome was unequivocal. The majority of students preferred the Skipable Action variant $\left(\chi^{2}=35.4, d f .2, p<0.001\right)$. This outcome fully agrees with theory. It indicates that the students favor a marking that enables users to scan and easily skip this kind of information. In addition, it supports the idea that for placement, the just-in-time criterion is the most critical one.

Practice was found to vary significantly from theory (see Table II, $\left(\chi^{2}=50.9, d f .3, p<0.001\right)$. In the manuals the problem-solving information was presented more often as an Afterthought than as a Skipable Action $\left(\chi^{2}=14.6\right.$, df. 2, $p<0.001)$. Unfortunately, most of these Afterthoughts in the manuals are presented late; $67 \%$ of these Afterthoughts refer to a problem the user would already have had to deal with. For example, an Afterthought to a seven-step procedure referred to a mistake the user might have made in step five.

Why does practice not concur with theory? One of the reasons may be that writers use the Afterthought variant to fit the presentation within a conceptual approach. They present the problem-solving information to make a general point, using it primarily for promoting some kind of general insight, attitude, or behavior rather than as a means to help users deal with the particular problem. The following example effectively illustrates this intent: "Should you receive the message "disk or directory full' you are in a situation from which it is impossible to recover your file. Always take care that the disk on which you want to save your data has enough free space."

Another reason that practice does not concur with theory may be that writers opt for the Afterthought variant out of convenience. Typically, regular task analyses ignore breakdowns, and writing is heavily biased in favor of presenting only instructions for flawless performances [42]. When the need for including problem-solving information shows up in testing, the writer faces a difficult decision on marking and placement. It is then often too late to do anything special, as the design options are limited. One of the most neutral solutions is to present the problem-solving information in the first few sentences of the nearest paragraph of text.

Another argument, related to convenience, is that sometimes similar problems can occur at several stages in the procedure. If these problems require identical solutions, writers may, for the sake of brevity, opt for a presentation as an Afterthought.

\section{Discussion}

The data show that the students strongly favor a presentation in which short sections of problem-solving information are given a distinct marking and a just-in-time placement. In addition, all of their arguments to support this choice fit very well with the arguments raised in the literature. In short, the design choices and considerations of the students concur with theory. However, this does not concur with practice. In most manuals, the problem-solving information that appears in the vicinity of a procedure is presented late, making it unfit for immediate use.

\section{CONCluSION}

From its early conception onward, the minimalist approach to documentation has stressed that users often face problems whose handling should be supported by the manual or program. Indeed, the principle to support error recognition and recovery, in which the word error means exactly the same as the word problem used in this paper, has always been one of the key design principles in minimalism [6], [7], [43]-[45].

Critics have expressed opposite views on the need to stress that manuals should support user problem solving. Some authors say that it is common practice, that conventional manuals already adequately offer this kind of help. Others emphasize that it is not common practice and that only minimal manuals adequately support problem solving of users. For example, Williams and Farkas [46] argue that "the minimalist position on error recovery is a position most of us would endorse as good, old-fashioned, common sense" (p. 41). In contrast, Draper and Oatley [47] state that "the most salient, single concrete technique (of minimalism) is to support error recognition and recovery. This is often the most obvious difference in content between a minimal manual and a conventional manual" (p. 226).

This inventory indicates that supporting the problem solving of users is not common practice. The (conventional) manuals 
that were analyzed failed to give adequate help. A major finding was that the problem-solving information was too hard to locate. Another major finding was that theory and practice are strongly at variance with one another in presenting problem-solving information. In this respect, the inventory serves mainly as food for thought, as a stimulus for writers to reconsider choices.

The inventory gives only a partial answer to the question of whether manuals adequately help users in handling problems. Many unresolved issues remain. Two very important ones are combining online and paper support, and examining the effects on users.

Combining Online and Paper Support: The inventory focused on the support given on paper, ignoring the online help for problem solving. Most companies (and users) want some support on paper and some online, which raises the question of what is to be presented where. In dealing with these questions at least two factors should be considered: user knowledge and skill, and the origin and effects of problems.

A strong advantage of support on paper is that navigating is relatively easy, that it does not tax the users' processing skills as much as online help. Among others, this suggests that novices should be given some problem-solving information on paper, before one can expect them to profit from online help. One type of help on paper that is likely to be beneficial for the novice as well as the expert is generalizable help, information that creates important insights or that fosters problem management. Experts too are often in need of such help, as "in many cases it is not just the pitiable novice but also the highly respectable expert who gets into trouble in the real computerized office world" [48, p. 326]. Generalizable help for the novice may consist of information about toggle keys or an explanation of the undo option.

Writers should also consider the origins and effects of problems when deciding which help should be given where. For example, some problems require a medium of presentation that works independently from the hardware or software so that users are not left unsupported when the hardware or software fails. And of course, paper manuals are unique for handling problems for which users cannot access the online help.

Two such unique situations are interruptions and crashes. Novices often need some help with interruptions such as unexpected (error) messages that appear during task execution. Without some support on paper, a novice may not understand the error message or know how to make it disappear (to close the window which presents it). Crashes effectively shut out all possibilities of accessing the online help. So, if a screen suddenly turns black, both the novice and the expert may be in need of some help on paper (or from a friend or help desk).

The insight that crashes should be discussed on paper is of course not new. In fact, detailed analyses of the data gathered in this inventory showed that writers tend to support system or program failures somewhat more frequently than other problem types such as slips and problems of a syntactic, semantic, or domain-based nature [38]. Interestingly, these analyses also indicated that $19 \%$ of the short sections of problem-solving information contained no information on how to solve the problem.
Writers might also want to consider their liability in deciding which help to put where. Severe problems that may damage the hardware or software or injure the user are probably best discussed both on paper and on line.

Examining the Effects on Users: Testing is invaluable for a number of reasons. First, testing is always needed when different theories or views contradict one another. Recall, for example, how authors may hold different opinions on the adequacy of problem-solving support offered by manuals when there is no evidence to support either stance. Second, testing is needed to show whether a design variation really makes a difference. Only tests can prove if it is the design variation and not some other factor that accounts for the outcome. And only tests can indicate whether the effect is substantial enough to warrant use in practice. Third, testing often brings to light new issues. For example, a recent test with eight (reference) manuals for WordPerfect showed that users may face yet another obstacle in accessing: lack of page precision [38]. The test showed that the indicated pages for the indexed keywords were often imprecise. Users frequently had to read three pages onward from the page indicated before reaching the problemsolving information. Interestingly, the test also showed that six of the eight manuals - with an average size of more than 1000 pages! - failed to give problem-solving information on a rather common printing problem.

This paper started by stating that the dearth of inventories poses a barrier to the advancement of technical writing as an applied science. The inventory was an attempt to reduce some barriers, tying theory and practice in various ways. It gives a state-of-the-art overview, but it is not a completed enterprise. It is a start that hopefully stimulates practitioners and researchers to bring forward their insights.

\section{ACKNOWLEDGMENT}

The author wishes to thank two anonymous reviewers for their comments on an earlier version of this paper, as well as B. Collis, for her help with editing.

\section{REFERENCES}

[1] R. J. Brockmann, Writing Better User Documentation: From Paper to Hypertext (Version 2). New York, Wiley, 1990.

[2] J. Price and H. Korman, How to Communicate Technical Information. Menlo Park, CA: Benjamin/Cummings, 1993.

[3] K. R. Woolever and H. M. Loeb, Writing for the Computer Industry. Englewood Cliffs, NJ: Prentice Hall, 1994.

[4] S. K. Card, T. P. Moran, and A. Newell, The Psychology of Human Computer Interaction. Hillsdale, NJ: Lawrence Erlbaum, 1983.

[5] J. M. Carroll and C. Carrithers, "Blocking learner error states in a training-wheels system," Human Factors, vol. 26, pp. 377-389, 1984.

[6] A. W. Lazonder, "Minimalist computer documentation, a study on constructive and corrective skills development," Ph.D. dissertation, Twente University, Enschede, The Netherlands, 1994.

[7] A. W. Lazonder and H. van der Meij, "Error-information in tutorial documentation: Supporting users' errors to facilitate initial skill learning" Int. J. Human Computer Studies, vol, 42, pp. 185-205, 1995.

[8] J. T. Dillon, "Problem finding and solving," J. Creative Behavior, vol, 16. pp. 97-111, 1982.

[9] M. J. Dreher, "Reading to locate information: Societal and educational perspectives," Contemp. Educ. Psychol., vol. 18, pp. 129-138, 1993.

[10] J. T. Guthrie and M. J. Dreher, "Literacy as search: Explorations via computer," in Cognition, Education, and Multimedia: Exploring Ideas in High Technology, D. Nix and S. Spiro, Eds. Hillsdale, NJ: Lawrence Erlbaum, 1990, pp. 65-113. 
[11] R. P. Kern, "Modeling users and their use of technical materials," in Designing Usable Texts, T. M. Duffy and R. H. Waller, Eds. Orlando, FL: Academic Press, 1985, pp. 341-175.

[12] D. A. Norman, The Psychology of Everyday Things. New York: Basic Books, 1988

[13] H. van der Meij, "Student questioning: A componential analysis," $J$. Individual Differences and Learning, vol. 6, no. 2, pp. 137-161, 1994.

[14] P. Wright, "Writing technical information," in Review of Research in Education, E. Z. Rothkopf, Ed. Washington, DC: Amer. Educ. Res. Assoc, 1987, pp. 327-385.

[15] J. W. Getzels, "The problem of the problem," in New Directions for Methodology of Social and Behavioral Science: Question Framing and Response Consistency, R. Hogarth, Ed. San Francisco, CA: Jossey Bass, 1982, pp. 37-49.

[16] J. W. Getzels, "Problem finding and creative thought," Questioning Exchange, vol. 2 , no. 2, pp. 95-103, 1988

[17] D. B. Paradice, "A question theoretic analysis of problem formulation: Implications for computer-based support," in Questions and Information Systems, T. W. Lauer, E. Peacock, and A. C. Graesser, Eds. Hillsdale, NJ: Lawrence EIlbaum, 1992, pp. 287-302.

[18] T. M. Duffy, J. E. Palmer, and B. Mehlenbacher, Online Help: Design and Evaluation. Norwood, NJ: Ablex, 1992.

[19] M. J. Dreher and J. T. Guthrie, "Cognitive processes in textbook chapter search tasks," Reading Res. Quart., vol. 25, pp. 323-339, 1990.

[20] M. F. Steehouder, "Informatie zoeken in computerhandleidingen: Een verkenning van problemen" (Information search in computer manuals: An exploration of problems), Tijdschrift voor Taalbeheersing, vol. 15, no. 1, pp. 3-12, 1993

[21] S. A. Karabenick, "Relation of perceived teacher support of student questioning to students' beliefs about teacher attributions for questioning and perceived classroom learning environment," J. Individual Differences and Learning, vol. 6, no. 2, pp. 187-204, 1994.

[22] A. Nadler, "Help-seeking behavior: Psychological costs and instrumental benefits," in Prosocial Behavior, M. S. Clark, Ed. Newbury Park, CA: Sage, 1991, pp. 290-311.

[23] . S. R. Yussen, A. D. Stright, and B. Payne, "Where is it? Searching for information in a college textbook," Contemp. Educ. Psychol, vol. 18, pp. $240-257,1993$.

[24] M. J. Dreher and R. F. Brown, "Planing prompts and indexed terms in textbook search tasks," J. Educ. Psychol., vol. 85, no. 4, pp. 662-669, 1993.

[25] F. W. Lancaster, Indexing and Abstracting in Theory and Practice. London, UK: Library Assoc., 1991.

[26] G. W. Furnas, T. K. Landauer, L. M. Gomez, and S. T. Dumais, "Behavioral evaluation and analysis of a hypertext browser," Commun. ACM, vol. 30, no. 11, pp. 964-971, 1987.

[27] M. F. Steehouder, "The quality of access: Helping users find information in documentation," in Quality of Technical Documentation, M. F. Steehouder, C. Jansen, P. van der Poort, and R. Verheijen, Eds. Amsterdam, The Netherlands: 1994, Rodopi, pp. 131-143.

[28]. B. B. Armbruster and J. A. Armstrong. "Locating information in text: A focus on children in the elementary grades," Contemp. Educ. Psychol., vol. 18, pp. 139-161, 1993.

[29] J. P. Byrnes and J. T. Guthrie, "Prior conceptual knowledge and textbook search," Contemp. Educ. Psychol., vol. 17, pp. 8-29, 1992.

[30] J. T. Guthirie, S. Weber, and N. Kimmerly, "Searching documents: Cognitive processes and deficits in understanding graphs, tables and illustrations," Contemp. Educ. Psychol, vol. 18, no. 2, pp. 186-221, 1993.

[31] P. Wright, "Quality or usability? Quality writing provokes quality reading," in Quality of Technical Documentation, M. F. Steehouder, C. Jansen, P. van der Poort, and R. Verheijen, Eds. Amsterdam, The Netherlands: Rodopi, 1994, pp. 7-38.
[32] S. Symons and M. Pressley, "Prior knowledge affects text search success and extraction of information," Reading Res. Quart., vol. 28, pp. $250-261,1993$.

[33] H. van der Meij and J. M. Carroll, "Principles and heuristics for designing minimalist instruction," Tech. Commun., vol. 42, no. 2, pp. 243-261, 1995.

[34] G. Nas, "Collecting descriptions of text-processing problems for a user-friendly manual," in Quality of Technical Documentation, M. W. Steehouder, C. Jansen, P. van der Poort, and R. Verheyen, Eds. Amsterdam, The Netherlands/Atlanta, GA: Rodopi, 1994, pp. 145-160.

[35] R. P. Carver, "Reading rate: Theory, research and practical implications," J. Reading, vol. 35, pp. 84-95, 1992.

[36] P. Sullivan and L. Flower, "How do users read computer manuals? Some protocol contributions to writers' knowledge," in Convergences: Transactions in Reading and Writing, B. T. Petersen, Ed. Urbana, IL: Nat. Council of Teachers of English, 1986, pp. 163-178.

[37] N. Ummelen, "Procedural and declarative information in software manuals. What do users actually use?" University of Twente, Enschede, The Netherlands, Internal Rep. 2, 1995.

[38] H. van der Meij, "Does the manual help? An examination of the problem-solving behavior of users, and the support manuals offer," University of Twente, Enschede, The Netherlands, Res. Rep., 1995.

[39] R. E. Horn, "Structured writing at twenty-five," Perform. Instruct., vol. 32, no. 2, pp. 11-17, 1993.

[40] H. van der Meij, "Catching the user in the act" in Quality of Technical Documentation, M. W. Steehouder, C. Jansen, P. van der Poort, and R. Verheyen, Eds. Amsterdam, The Netherlands/Atlanta; GA: Rodopi, 1994, pp. 201-211.

[41] The Chicago Manual of Style, 13th ed. Chicago, IL: Univ. Chicago Press, 1982

[42] J. M. Carroll and H. van der Meij, "Ten misconceptions about minimalism," IEEE Trans. Prof. Commun, vol. 39, no. 2, pp. 72-86, 1996.

[43] . J. M. Carroll, "Minimalist training," Datamation, vol. 30, pp. 125-136, 1984.

[44] ㄴ. The Nurnberg Funnel: Designing Minimalist Instruction for Practical Computer Skill. Cambridge, MA: MIT Press, 1990.

[45] _ "Techniques for minimalist documentation and user interface design," in Quality of Technical Documentation, M. F. Steehouder, C. Jansen, P. van der Poort and R. Verheijen, Eds. Amsterdam, The Netherlands/Atlanta, GA: Rodopi, 1994, pp. 67-75.

[46] T. R. Williams and D. K. Farkas, "Minimalism reconsidered: Should we design documentation for exploratory learning?"' SIGCHI Bull., vol. 24, no. 2, pp. 4l-50, 1992

[47] S. W. Draper and K. Oatley, "Action centered manuals or minimalist instruction? Alternative theories for Carroll's minimal manuals," in Computers and Writing: State of the Art, P. Holt and N. Williams, Eds. Oxford, UK: Intellect Books, 1990, pp. 222-243.

[48] J. Prümper, D. Zapf, F. C. Brodbeck, and M. Frese, "Some surprising differences between novice and expert errors in computerized office work," Behav. Inform. Technol, vol. 11, no. 6, pp. 319-328, 1992.

Hans van der Meij is a Researcher at the Faculty of Instructional Technology at Twente University, Enschede, The Netherlands. His main fields of study are questioning behavior and technical documentation. In the latter area he has started his work by examining minimalism. While continuing his work on minimalism he is now also surveying the state-of-the-art in technical documentation through a number of inventories. These inventories focus on issues such as warnings, introductions, action commands, problem-solving information, and the combination of on-paper and online support. They are an attempt to link theory (and empirical research) with practice and thereby to advance technical writing as an applied science. 